\title{
A Cooperação Sul-Sul em saúde, segundo organismos internacionais, sob a perspectiva da bioética crítica
}

South-South cooperation in health, by international organizations,
under the perspective of critical bioethics

Samira Santana de Almeida', Cláudio Fortes Garcia Lorenzo²

RESUMO A Cooperação Sul-Sul em saúde apresenta-se como alternativa ao caráter assistencialista e de transferência de tecnologias que marca o antigo modelo Norte-Sul. As ações dela decorrentes têm uma dimensão ética evidente, já que envolvem alocação de recursos, relações interculturais, compartilhamento de biotecnologias e processos decisórios coletivos. No presente ensaio, é apresentado o modelo de bioética crítica a partir do qual se analisam três importantes documentos internacionais contendo diretrizes para a Cooperação Sul-Sul, com vistas a compreender em que medida favorecem a construção de programas estruturantes e emancipatórios.

PALAVRAS-CHAVE Cooperação internacional; Bioética; Políticas públicas de saúde.

ABSTRACT The South-South Cooperation in health is presented as an alternative to the welfare character and transfer of technologies that mark the old North-South model. The resulting actions that come from it have a clear ethical dimension, as they involve resources allocation, intercultural relations, biotechnology sharing and collective decision processes. In this current essay, it is presented the critical bioethics model from which are analyzed three important international documents containing guidelines for the South-South cooperation, in order to understand to which extent they favor the construction of structuring and emancipatory programs.

KEYWORDS Internacional cooperation; Bioethics; Public health policies.

\footnotetext{
1 Universidade de Brasília (UnB), Programa de PósGraduação em Bioética - Brasília (DF), Brasil. samisantanaa@gmail.com

2 Universidade de Brasília (UnB), Programa de Pós-Graduação em Bioética e Programa de Pós-Graduação em Saúde Coletiva - Brasília (DF), Brasil.

claudiolorenzo.unb@gmail. com
} 


\section{Introdução}

A cooperação internacional é a reunião de vários estados e outros atores internacionais para coordenar esforços em busca de objetivos supostamente comuns, na forma de alianças temporárias, coalizões mais ou menos duradouras e processos de integração regional (OBSERVATÓRIO BRASIL E O SUL, 2015). Pode ser bilateral, multilateral e triangular, sendo esta última - quando a doação e a recepção se dão entre dois países e um terceiro - a executora das ações (TORRONTEGUY; DALLAR, 2012).

A saúde passou a se tornar um objeto mais frequente de cooperação internacional com a publicação, em 1951, do 'Regulamento Sanitário Internacional', pela Organização Mundial de Saúde (OMS), que consistia em um conjunto de regras para o controle de doenças infecciosas (ALMEIDA ET AL., 2010). As endemias, em países tropicais, causavam problemas às relações comerciais, devido às quarentenas dos navios nos portos, e começavam a atravessar mais facilmente as fronteiras, dado o rápido crescimento da aviação comercial. Nos anos seguintes, ela se fortalece e os programas se expandem por questões de segurança no período da Guerra Fria (OLIVEIRA; LUZIVOTTO, 2008).

O modelo Norte-Sul de cooperação internacional em saúde tinha caráter explicitamente assistencial e consistia na transferência de conhecimentos e tecnologias dos países avançados àqueles menos desenvolvidos, por meio da qual era reafirmada a condição de subalternidade destes. Entretanto, com o avanço das disparidades entre países ricos e pobres, foi ficando cada vez mais claro que esse modelo não seria capaz de responder às necessidades dos países em desenvolvimento, uma vez que persistia e evoluía ligado, primordialmente, à expansão dos mercados para as indústrias farmacêuticas, de equipamentos e insumos e aos interesses financeiros e políticos dos países centrais.

Com a disseminação mundial de epidemias de Síndrome da Imunodeficiência Adquirida (Aids) e de outras doenças infectocontagiosas fatais, os sistemas de saúde dos países de baixa renda ficaram sobrecarregados. $\mathrm{O}$ acesso aos serviços de saúde foi, aos poucos, sendo privatizado, devido ao efeito devastador da globalização econômica desigual. Hoje, por exemplo, em sete dos 12 países da América do Sul, a participação dos gastos públicos com os gastos totais em saúde não alcança 60\% (GIOVANELLA ET AL., 2015). Houve, consequentemente, negligência com as questões epidemiológicas e com as atividades de saúde pública, prevenção e controle de endemias, doenças transmissíveis e epidêmicas (ALMEIDA, 2006).

Em 1978, a Organização das Nações Unidas (ONU) estabelece a Unidade Especial para a Cooperação Sul-Sul com o propósito de diminuir a dependência dos países em desenvolvimento dos programas de ajuda dos países desenvolvidos (SANTANA; FERREIRA, 2010). Até o momento presente, diversos programas de Cooperação Sul-Sul intra e inter-regionais foram elaborados e postos em execução, envolvendo todas as regiões do planeta (ROA; SANTANA, 2011). Esse novo modelo nasce, portanto, como uma alternativa ao modelo NorteSul e anuncia sua identidade e distinção por ser conduzido por princípios de horizontalidade, consenso e equidade (SEGIB, 2008).

Nas últimas três décadas, o Brasil credenciou-se a participar de diversos programas de cooperação internacional Sul-Sul e assumiu um lugar de protagonista enquanto prestador a países menos desenvolvidos. Só entre 2005 e 2009 , investiu mais de US\$1,4 bilhão em cooperação internacional para o desenvolvimento (FEDATTO, 2015). No caso da Iniciativa Global de Erradicação da Pólio, o País teve uma atuação reconhecida com as estratégias adotadas, que tornaram-se referências internacionais (DURANTE; DAL POZ, 2014). A Fundação Oswaldo Cruz (Fiocruz) tem sido a instituição brasileira de maior destaque (FEDATTO, 2015), com diversos programas dirigidos a países latino-americanos e 
africanos de língua portuguesa.

Apesar de ter princípios próprios, a Cooperação Sul-Sul em saúde envolve alocação de recursos, relações interculturais em torno da elaboração e da implementação de políticas públicas, do desenvolvimento e do compartilhamento de biotecnologias e de processos decisórios coletivos para definição de prioridades. Ela traz, portanto, uma incontornável dimensão ética que precisa ser discutida, mas que vem sendo negligenciada pela literatura, mesmo considerando que a produção científica em bioética venha incorporando a análise de conflitos em escala cada vez mais global (CUNHA; LORENZO, 2014).

Os documentos internacionais que portam diretrizes para a Cooperação Sul-Sul em saúde são elementos importantes por estabelecerem as bases sobre as quais serão elaborados os acordos. É importante analisar em que medida essas diretrizes apontam para a construção de programas estruturantes e emancipatórios ou tendem a reproduzir os modelos Norte-Sul, onde os interesses transnacionais dos governos e as metas das instituições públicas ou privadas dos países em melhores condições estarão acima das demandas dos países mais pobres.

A América Latina (e, muito especialmente, o Brasil) tem se destacado pela construção de modelos teóricos em bioética que se opõem aos modelos hegemônicos, que excluem de seu campo os problemas sanitários e a vulnerabilidade social em saúde enquanto objeto de análise. Eles tentam demonstrar as dificuldades de avanços éticos nas relações internacionais, dada a manutenção das condições estruturais que perpetuam as disparidades globais (CUNHA; LORENZO, 2014). A bioética crítica é um desses modelos (LORENZO, 2012).

O objetivo do presente artigo foi produzir uma análise crítica de três documentos normativos considerados fundamentais para a orientação das ações de Cooperação Sul-Sul, tendo como referencial os componentes analíticos da bioética crítica.

\section{Bioética crítica: fundamentos e categorias analíticas para pensar a cooperação internacional em saúde}

A cooperação internacional em saúde implica, necessariamente, cálculos de situação de saúde e planejamento de ações que influenciarão diretamente nas formas cotidianas das vidas das populações envolvidas. Pode-se dizer, portanto, tratar-se de uma biopolítica, tal como descrita por Foucault (1994), na medida em que constitui uma regulamentação para efetivar e administrar os dispositivos de exercício do poder sobre a vida de populações. Só que, no caso da cooperação internacional, essa biopolítica não está endogenamente restrita a um Estado, mas atravessa fronteiras em direção a nações e povos diversos.

No modelo de Cooperação Norte-Sul em saúde, era evidente a existência de uma biopolítica transnacional que guardava os objetivos de domesticação e docilização de corpos para o crescimento do contingente populacional apto para integrar os processos de produção capitalista e a expansão das relações de mercado, tal como descrito por Foucault (1979). Assim, melhorava-se a salubridade de países considerados epidemiologicamente inóspitos, facilitando a presença dos agentes estrangeiros da cooperação, ao tempo em que se expandia o consumo de bens de saúde produzidos pelas grandes indústrias de medicamentos e insumos.

Existe, hoje, uma clara hegemonia de uma lógica gerencial das políticas públicas baseadas na racionalidade econômica neoliberal, que, sendo incapaz de garantir a governança das nações por meio da legitimidade da soberania estatal, busca essa legitimidade a partir do fortalecimento do mercado (souzA; CUNHA, 2013). Junges (2009), indica uma reconfiguração do biopoder, em que o Estado vai cedendo lugar ao mercado, tanto no 
exercício de um poder real quanto simbólico, considerando, consequentemente, que a biopolítica já não se encontra, na atual fase do capitalismo, restrita ao Estado.

A inquietação principal, com relação à Cooperação Sul-Sul em saúde, é que ela venha a repetir, na prática, as mesmas diretrizes da Cooperação Norte-Sul, em que as relações de dominação apenas se alternarão dos países ricos do Norte com relação aos países pobres do Sul para os dos países emergentes do Sul com relação aos países pobres do Sul.

Uma abordagem bioética desse problema precisa ser feita a partir de modelos teóricos que não estejam baseados na cisão entre ética e política, nem privilegie apenas as dimensões biomédicas dos conflitos, como é típico dos modelos hegemônicos de bioética produzidos nos países do Norte (GARRAFA, 2012). Necessitamos de um modelo desenvolvido desde o Sul e que contenha categorias analíticas capazes de refletir sobre a moralidade nas relações entre Estados e povos, sobre o papel do mercado na geração dos conflitos éticos em saúde, sobre os desafios para o respeito à diversidade nas práticas de saúde exercidas em contextos de interculturalidade.

A bioética crítica (LORENZO, 2012) vem sendo desenvolvida por um processo de articulação entre elementos da teoria crítica a partir da obra de autores da Escola de Frankfurt, como Horkheimer, Marcuse e Habermas, e dos estudos da colonialidade de autores como Quijano (2005), Mignolo (2008) e Segatto (2010). A bioética crítica compreende a existência de uma falsa neutralidade da ciência e identifica uma ideologia de dominação por trás da própria constituição da racionalidade científica. Daí que, para ela, o atual complexo científico-tecnológico-industrial constitui-se no mais exitoso resultado histórico da fusão entre mercado, Estado e ciência, contribuindo para que as formas atuais de produção e distribuição de ciência e tecnologia representem os elementos centrais para o exercício do poder de um Estado ou de um povo sobre outro.

Para esse modelo teórico de bioética, a história deve ser a via pela qual se busca compreender as atuais estruturas de poder estabelecidas entre as sociedades, os Estados, as empresas e os organismos internacionais, de onde, por sua vez, surgem os conflitos éticos em torno da saúde global. Assim sendo, cada fato social em análise não deve ser tomado como uma realidade estanque, a qual nos cabe apenas compreender, mas como resultado de um processo histórico, que pode e deve ser alterado. Contribuir para a descoberta ou a criação dessas vias de transformação da realidade representa um dos principais objetivos da bioética crítica.

Cunha (2014) trouxe uma importante contribuição à bioética crítica para análises de conflitos éticos em saúde global, ao integrar o pensamento de Cox (1987), autor muito próximo da teoria crítica. Derivando das teorias desse autor sobre a organização do sistema mundo vigente, a bioética crítica compreende a existências de três forças centrais em âmbito global: a primeira força é o domínio das capacidades materiais, representadas pelos recursos financeiros e meios de produção; a segunda força é o domínio das ideias, a partir de sua homogeneização e difusão em meios de comunicação; e, finalmente, a terceira força é a articulação, no interior das instituições, entre capacidades materiais e ideias, com o fim de estabilizar o ordenamento social vigente (CoX, 1987). Daí que as relações internacionais estão envoltas em uma 'grande nebulosa', definida como um composto difuso e volátil de grande densidade que dificulta a visão da sociedade sobre como se organizam e se reproduzem os padrões hegemônicos de poder. Fazem parte dessa nebulosa, instituições e organismos internacionais, tais como o Fundo Monetário Internacional (FMI), o Banco Mundial e a Organização Mundial do Comércio (OMC).

Também vem de Cox (1987) a compreensão assumida pela bioética crítica de que a 
globalização exportou os padrões de hierarquia do capitalismo a todos os povos e nações envolvidos, perpetuando relações de poder que se encontram estruturadas em três níveis de inserção social dos indivíduos e das populações: 1. Os integrados, representados por aqueles inseridos na máquina produtiva pública ou privada e tendo uma posição de relativo bem-estar; 2 . Os precarizados, que servem à economia global com baixos salários, pouca perspectiva de mudança e que são facilmente substituíveis; e 3. Os excluídos, que são aqueles que não se encaixam no sistema produtivo e são considerados descartáveis pelo mercado financeiro global.

Os estudos da colonialidade cumprem, na fundamentação da bioética crítica, uma expansão da compreensão das relações entre os Estados centrais e periféricos e estruturam sua visão de interculturalidade, raça, racismo e etnocentrismo, objetos sobre os quais a teoria crítica é omissa. Esses elementos são indispensáveis para pensar as questões das práticas de saúde, assim como de produção e distribuição de tecnologias, envolvendo países do Sul geopolítico.

Assim sendo, a bioética crítica assume a crítica à modernidade inaugurada pelos estudos da colonialidade, quando estes demonstram que todas as formas oficiais de relações de poder e de produção de saber globalmente instituídos, encontram-se orientadas pelo ideal de modernidade europeu, considerado o auge da produção epistemológica e cultural da humanidade e dentro do qual a noção de raça foi constitutiva para a afirmação da superioridade do colonizador e do seu direito de civilizar os demais povos (CASTRO-GOMEZ, 2005). Para a bioética crítica, são claramente coloniais as teorias desenvolvimentistas onde crescimento e bem-estar não conseguem ser compreendidos fora de uma perspectiva econômica globalizada e de uma contínua evolução tecnológica.

A colonialidade cria um controle aberto e tácito em proporções globais, apoiada num quadro de pensamento que legitima a superioridade entre países, sociedades, sujeitos e conhecimentos (BALLESTRIN, 2013). O sistema mundo estaria, portanto, constituído por uma complexa estrutura de poder com vários níveis entrelaçados, entre os quais: $o$ controle da economia; o controle da autoridade; o controle da natureza e dos recursos naturais; o controle do gênero e da sexualidade; e, por fim, o controle da subjetividade e do conhecimento. Não existiria, portanto, modernidade sem colonialidade (RESTREPO; ROJAS, 2010).

Vale observar que o conceito de colonialidade amplia o conceito foucaultiano de 'poder disciplinar', uma vez que já não se detém no interior de um Estado e transcende as fronteiras das potências hegemônicas. Desta forma, cria identidades homogêneas globais que facilitam a elaboração de acordos e leis internacionais favoráveis a elas, na tentativa de assegurar uma perene dependência econômica e um fluxo ininterrupto de matérias-primas dos países periféricos em direção ao centro e de produtos industrializados em sentido contrário (QUIJANO, 2005).

Além da relação entre Estados-Nação, a cooperação internacional em saúde resulta, também, de relações entre povos culturalmente distintos, seja no interior de um mesmo país, seja entre povos distintos de distintos países, o que demonstra a importância das relações interculturais em torno da escolha e da implementação das novas práticas de saúde, bem como para a aplicação de tecnologias advindas da cooperação estabelecida.

Os estudos da colonialidade e, consequentemente, a bioética crítica negam as definições romantizadas e acríticas de interculturalidade, frequentemente utilizadas pelos organismos internacionais, onde parece simples estabelecer uma interação equitativa de diversas culturas e a possibilidade de gerar expressões culturais compartilhadas, adquiridas por meio do diálogo e de uma atitude de respeito mútuo (UNESCO, 2009). Para Segatto (2010), há uma tensão entre 
a afirmação das identidades culturais frente ao papel do Estado, que perpetua a dependência por meio de uma colonização tácita normatizadora, que regula as populações. É, portanto, indispensável estar atento às dificuldades práticas do diálogo intercultural determinado pelos poderes historicamente constituídos entre culturas, etnias e raças.

Com base nesse referencial teórico, constituímos quatro categorias para a análise dos três documentos escolhidos: 1. A abordagem relativa ao acesso ao saber científico e à produção científico-tecnológica, buscando investigar em que medida estão alinhados a uma noção dominadora e colonial da relação entre os países ricos e pobres em torno do saber e do poder; 2. Se as razões históricas que produziram as disparidades socioeconômicas entre os países são reconhecidas, e, nesse sentido, como são compreendidos a pobreza e os outros determinantes de saúde; 3. De que forma é tratada a participação na Cooperação Sul-Sul das empresas privadas e dos organismos internacionais não governamentais; 4 . Abordagem dada ao contexto de interculturalidade e às relações etnorraciais, em torno da elaboração e da implementação das ações previstas nos acordos de cooperação internacional.

\section{Documentos normativos para a Cooperação Sul-Sul em saúde na perspectiva da bioética crítica}

Diversos documentos internacionais foram desenvolvidos com vistas a estabelecer diretrizes e novos paradigmas para a Cooperação Sul-Sul em saúde. A Biblioteca Virtual em Saúde (BVS) do Núcleo de Estudos sobre Bioética e Diplomacia em Saúde (Nethis), da Fiocruz, disponibiliza todos os documentos relacionados à Cooperação Sul-Sul produzidos até o momento para todas as regiões do planeta.
Foram selecionados, por conveniência, três deles, representando três níveis distintos de abrangência geopolítica. Um de amplitude global, que marca o reconhecimento das Nações Unidas da importância da Cooperação Sul-Sul, que é a 'Resolução da Conferência de Alto Nível das Nações Unidas sobre Cooperação Sul-Sul' (ONU, 2009); um especialmente formulado para a região das Américas, intitulado 'A saúde e as relações internacionais: seu vínculo com a gestão do desenvolvimento nacional da saúde' (OPAS; OMS, 2008), e, finalmente, o 'Plano Estratégico de Cooperação em Saúde da Comunidade de Países de Língua Portuguesa (Pecs/CPLP) 2009-2012' (CPLP, 2009), dentro do qual o Brasil assume um protagonismo evidente.

Ao analisarmos os documentos, encontramos uma diferença significativa de abordagem entre os dois primeiros documentos elaborados no contexto da ONU, Organização Pan-Americana da Saúde (Opas) e o documento da Comunidade de Países de Língua Portuguesa (CPLP).

A Resolução da ONU reconhece, no seu $12^{\circ}$ enunciado, a existência de diferenças na concepção da Cooperação Sul-Sul, quando afirma:

We recognize that South-South Cooperation takes different and evolving forms, including, inter alia, the sharing of knowledge and experiences, training, technology transfer [...]. (ONU, 2009, P. 2).

Todavia, no $20^{\circ}$ enunciado, ao definir um dos seus objetivos, o documento estabelece: "emphasize the need to promote, 'including through South-South cooperation', access to and the transfer of technology" (ONU, 2009, P. 4). Ora, a existência da expressão (destacada) 'inclusive por meio da Cooperação Sul-Sul' parece revelar uma aceitação naturalizada de que a transferência de tecnologia e a promoção do acesso ao conhecimento são próprias dos países do Norte, e que aqui estão sendo permitidas 'inclusive' aos países do Sul. Isso, além de demonstrar uma concepção restrita 
do que seja tecnologia, revela as marcas de uma compreensão de tendência colonial sobre cooperação internacional.

Outro elemento importante é o destaque dado à função dos fundos específicos dos organismos internacionais como via principal para o financiamento, como demonstra o $10^{\circ}$ enunciado:

We reaffirm the key role of the United Nations, including its funds, programmes, specialized agencies and regional commissions, in supporting and promoting cooperation among developing countries. (ONU, 2009, P. 2).

Entre essas agências encontra-se, por exemplo, o Banco Mundial, onde sabidamente a influência de países ricos e pobres nas decisões é bastante assimétrica.

Essa naturalização da posse do saber e da ciência, e com tonalidades claramente coloniais, é reforçada pela absoluta falta de orientação relacionada aos conflitos de interesse que podem envolver empresas e instituições privadas em sua participação nos acordos de cooperação internacional em saúde. A participação do setor privado e de instituições não governamentais é tratada como se movida pelos mesmos interesses e responsabilidades do Estado.

O conteúdo central do documento que demonstra essa perspectiva está resumido no enunciado 19:

South-South Cooperation embraces a multistakeholder approach, including non-governmental organizations, the private sector, civil society, academia and other actors that contribute to meeting development challenges and objectives in line with national development strategies and plans. (ONU, 2009, P. 3).

A colocação de todos os atores citados, incluindo o 'setor privado', como se partilhassem dos mesmos interesses, contribui para a manutenção de uma 'grande nebulosa' que nos impede de enxergar como essas relações de poder interferem na saúde global. A Resolução da ONU parece ignorar, por exemplo, que o grupo das chamadas doenças negligenciadas, para as quais existem poucos estudos e tratamentos disponíveis é fruto da falta de interesse da grande indústria farmacêutica por enfermidades que atingem países em desenvolvimento, bem como da ausência de regulação pelos Estados da produção dessa indústria. No mesmo sentido, parece desconhecer que os altos preços praticados por essas empresas sobre tecnologias indispensáveis, tais como as drogas antirretrovirais constituem uma das razões da inacessibilidade de grandes contingentes populacionais, já que os sistemas públicos de saúde de seus países não conseguem pagá-los.

O documento da Opas segue uma perspectiva semelhante, menos acentuada na divisão de papéis entre países desenvolvidos e em desenvolvimento, provavelmente por ter entre os 47 países que a compõem apenas 2 considerados desenvolvidos. Ele segue, entretanto, a tendência do modelo Norte-Sul de cooperação ao dar uma ênfase maior aos problemas sanitários envolvidos com doenças infectocontagiosas capazes de atingir outros países e menor nos processos de intercâmbio em ciência e tecnologia de forma estruturante para os países em desenvolvimento.

No enunciado 21, por exemplo, ao apontar os principais objetivos para as políticas e ações que requerem cooperação, ele afirma essa especial importância “[...], sobretudo, diante de problemas da saúde e riscos que ultrapassam fronteiras" (OPAS, 2008, P. 6). O que, obviamente, tem maior potencial de ameaçar interesses comerciais e militares.

A questão do desenvolvimento científico e tecnológico é abordada apenas uma vez no $15^{\circ}$ enunciado, de forma ainda atrelada a questões sanitárias das doenças infectocontagiosas, sem deixar claro como promovê-lo e acessá-lo: 
No campo das relações internacionais cresceu a compreensão de que existe um amplo leque de assuntos sanitários e de consequências para a saúde com o desenvolvimento científico e tecnológico acelerado, que transcendem as fronteiras nacionais e que requerem a ação mundial. (OPAS, 2008, P. 4).

Já a questão dos interesses privados é tratada na mesma perspectiva acrítica e sem recomendações específicas para a proteção dos interesses públicos ou conflitos de interesse envolvidos. Vale destacar o $14^{\circ}$ enunciado quando afirma:

Além disso, se observou uma mostra da convergência de interesses comerciais e sanitários em 2002 e 2003 com o surto da Síndrome de Insuficiência Respiratória Severa (SARS). (OPAS, 2008, P. 4).

Ora, uma afirmação desse caráter não é seguida por nenhum comentário sobre se essa convergência foi positiva ou negativa, ou quais foram os principais beneficiários, ou se deve implicar atenção especial na elaboração de acordos, no sentido de proteger o interesse público.

Mantém-se, portanto, a mesma perspectiva acrítica da Resolução da ONU com relação à participação dos setores privados. Em um quadro síntese exibido pelo documento sobre as mudanças ocorridas no cenário da cooperação internacional em saúde (OPAS, 2008, P. 7), é apresentada a "proliferação de atores transnacionais", entre os quais, são citados "o setor corporativo de negócios" e as "empresas com fins lucrativos". Em outro item do mesmo quadro é afirmado o

Crescente envolvimento do setor privado no desenvolvimento de políticas públicas, particularmente de agentes privados de países desenvolvidos influenciando políticas públicas nos países em desenvolvimento. (OPAS, 2008, P. 7).

Essa realidade é apontada como um fator que torna mais complexos os processos de elaboração de acordos, mas não é explicitamente demonstrada qualquer preocupação sobre em que medida essas relações público-privadas podem funcionar como instrumento de domínio de países sobre outros ou sobre o risco existente em se desenvolver políticas públicas conduzidas por interesses privados. Ou seja, a nova modalidade de biopolítica, conduzida pelo mercado, da qual falava Junges (2009), parece plenamente naturalizada e aceita.

Pode-se compreender que documentos diplomáticos sejam cuidadosos e pouco enfáticos ao comentar modelos políticos ou atuações governamentais de seus Estados membros, mas não se justifica uma postura acrítica relativa aos setores privados da saúde, sobretudo, considerando-se os dados históricos que temos sobre a atuação dos mesmos. Isso pode nos levar a compreender a postura da Opas, como incluída naquela terceira força do sistema mundo à qual se referia Cox (1987), que articula, dentro das instituições, as outras duas forças principais, o domínio das capacidades materiais e o domínio das ideias.

Nem a Resolução da ONU nem o documento da Opas fazem qualquer menção seja ao processo histórico envolvido nas disparidades socioeconômicas dos países, seja a determinantes de saúde. Esses fatores são invariavelmente apresentados como realidades estanques, desprovidas de causas.

Algo que chama especialmente a atenção é o fato de que documentos dirigidos a países constituídos em grande número por significativos contingentes de povos tradicionais sejam completamente omissos com relação aos cuidados necessários no contato com populações culturalmente distintas, tanto em torno da implementação das ações quanto dos conflitos etnorraciais que podem delas derivar. O silêncio em torno da diversidade cultural e de como saberes tradicionais 
necessitam ser articulados nas práticas de saúde é típico de uma visão colonial, que desvaloriza as diferenças e os saberes locais e pretende imprimir o modelo do centro na periferia.

O terceiro documento que nos propusemos examinar, o Pecs/CPLP, apresenta algumas posturas significativamente distintas dos dois documentos anteriores.

No tocante à produção científico-tecnológica, surge entre suas diretrizes orientadoras (CPLP, 2009, P. 5) a noção de "complexo produtivo comunitário” como caminho para maior acesso a insumos estratégicos, o que é bem diferente da tendência dos documentos anteriores de manter cooperação triangular com países desenvolvidos para esse fim. No mesmo sentido, o eixo estratégico 2 cita em um de seus objetivos "o estabelecimento de práticas técnico-científicas colectivas, interactivas e interdisciplinares", e o eixo estratégico 3 se refere à ação conjunta de pesquisadores da CPLP "mediante geração e apropriação de conhecimento". Não há dúvida de que são abordagens ancoradas em perspectivas políticas e epistemológicas bastante distintas, onde os sujeitos alvos da cooperação estão bem melhor incluídos.

A parceria público-privada está prevista, mas tem muito menor destaque que nos documentos anteriores. Aqui é afirmada, de maneira muito mais clara, a necessidade de criar estruturas de produção internas e independentes, como observa-se em um dos objetivos do eixo estratégico 4: "reduzir a dependência externa de insumos para a saúde, [...] e ampliar o acesso à assistência farmacêutica" (CPLP, 2009, P. 10), mostrando-se bastante distinta do foco em transferência de tecnologia, presente nos documentos da ONU e da Opas.

O Pecs/CPLP também parece buscar alternativas aos fundos de investimento da ONU para o financiamento de seus projetos de cooperação, tal como indicado em seu item 7.2 sobre financiamento: mecanismo financeiro próprio a criar para o efeito, por organizações internacionais e outros parceiros de desenvolvimento, tendo sempre em atenção o princípio da sua harmonização com os Planos Nacionais de Saúde de cada Estado membro. (CPLP, 2009, P. 12).

Da mesma forma que os outros documentos analisados, o Pecs/CPLP não aborda as razões históricas das diferenças entre os países, mas ele é o único que reconhece de forma explícita a necessidade de enfrentar os determinantes sociais de saúde, inclusive em suas diferenças de gênero, e, também, o único a mencionar como prioridade as populações vulneráveis. Entre os objetivos, está definido que:

o Pecs deverão ter em atenção o facto de que as assimetrias e desigualdades em saúde reflectem e são reflexo das desigualdades e discriminações de base sociocultural e económica entre mulheres e homens. (CPLP, 2009, P. 4),

e as diretrizes orientadoras indicam "priorizar populações de maior vulnerabilidade" (CPLP, 2009, P. 5).

A questão da interculturalidade aparece, não entre objetivos e diretrizes orientadores, mas entre os projetos estruturantes relacionado ao eixo estratégico 7 da proteção e promoção da saúde. Lá encontramos:

Implantação de um Programa de sensibilização de curandeiros, bruxos e outros 'médicos e parteiras tradicionais' para o reconhecimento e derivação ao sistema de saúde de patologias específicas. (CPLP, 2009, P. 12).

É, portanto, o único que, pelo menos, reconhece a existência de saberes tradicionais e de detentores desses saberes na cultura local, bem como da necessidade de articulá-los com as ações previstas.

Não obstante, a abordagem da interculturalidade no documento permanece insuficiente para orientar cooperações 
internacionais entre países nos quais existe um contingente significativo de comunidades tradicionais. Mantém-se ainda claramente a noção colonial de 'superioridade de saberes', uma vez que o documento propõe uma sensibilização 'unidirecional', como se não fosse importante também sensibilizar os profissionais da ciência convencional aos saberes tradicionais e, como se nada houvesse a aprender com eles. Essa postura dificulta, sem dúvidas, uma construção conjunta de estratégias e ações de saúde.

Pode-se também constatar que, da mesma forma que nos demais documentos, as questões propriamente etnorraciais envolvendo as práticas derivadas da cooperação não são abordadas.

\section{Considerações finais}

A criação do consenso dentro da ONU de que a saúde constitui um elemento imprescindível ao desenvolvimento ocorreu concomitantemente a uma reconfiguração geopolítica, devido ao fim da guerra fria e ao surgimento dos chamados 'países emergentes', criando uma atmosfera favorável ao desenvolvimento de propostas estruturantes para a Cooperação Sul-Sul em saúde, que pretendem oferecer alternativas ao antigo modelo Norte-Sul e dele distinguem-se por se encontrarem fundadas na noção de soberania compartilhada e nos princípios de horizontalidade, consenso e equidade.

Entretanto, existem desafios ideológicos e práticos para a ONU, relacionados aos diversos contextos de aplicação, que tornam o cumprimento desses princípios muito mais complexo do que pode parecer no primeiro momento. Há sempre uma tendência a fazer com que os Estados se tornem meros instrumentos de adaptação das políticas domésticas ao sistema mundo orquestrado pelos países centrais. $\mathrm{E}$ isso pode ocorrer também por meio dos acordos de Cooperação Sul-Sul em saúde.

A análise de documentos contendo diretrizes para esse modelo de cooperação, sobretudo quando formulados no âmbito da ONU e de suas instituições regionais, demonstra que os organismos internacionais têm grande dificuldade em se libertar dos antigos modelos de cooperação. A posse de capacidades materiais e de ideias, incluindo aqui os meios e fins para o desenvolvimento científico e tecnológico por meio das empresas privadas e corporações de comércio internacional, é tomada acriticamente como parceira. Esse processo legitima uma pretensa superioridade dos organismos internacionais e torna difícil compreender a heterogeneidade dos contextos socioeconômicos e culturais, bem como as razões históricas das disparidades de saber e poder existentes, e as responsabilidades que elas implicam.

Por outro lado, formulações, como o Pecs/ CPLP, oriundas de associações de países em contextos mais independentes de organismos internacionais, fundos de investimento e empresas privadas, integrantes da 'grande nebulosa' da saúde global, parecem oferecer melhores possibilidades em se constituir enquanto programas estruturantes e emancipatórios.

Chama atenção em todos os documentos a falta de orientações mais adequadas para lidar com o contexto de interculturalidade em torno da implementação das práticas de cooperação.

Evidentemente, essa avaliação dos documentos normativos é insuficiente para analisar como estão sendo verdadeiramente implantadas as ações de Cooperação Sul-Sul em saúde entre os países envolvidos, e, portanto, pesquisas observacionais de campo precisarão ser desenvolvidas para dar, no futuro, uma resposta a tal questão. 


\section{Referências}

ALMEIDA, C. M. Health Sector Reform in Latin America and the Caribbean: the role of International organizations in formulating agendas and implementing policies. Well-being and social policy, Genebra, v. 2, n. 1, p. 123-160, 2006.

ALMEIDA, C. M. et al. A concepção brasileira de "cooperação Sul-Sul estruturante" em saúde. RECIIS, Rio de Janeiro, v. 4, n. 1, p. 25-35, mar. 2010.

BALLESTRIN, L. América Latina e o giro decolonial. Rev. Bras. Ciênc. Polít., Brasília, DF, n. 11, p. 89-117, maio/ago. 2013.

CASTRO-GÓMEZ, S. Ciências sociais, violência epistêmica e o problema da "invenção do outro". In: LANDER, E. (Org.). A colonialidade do saber: eurocentrismo e ciências sociais, perspectivas latinoamericanas. Buenos Aires: CLASCO, 2005. p. 169-186.

\section{COMUNIDADE DOS PAÍSES DE LÍNGUA}

PORTUGUESA (CPLP). Plano Estratégico de Cooperação em Saúde da CPLP (PECS/CPLP) 2009-

2012. [Internet], 2009. Disponível em: $<$ http://

bioeticaediplomacia.org/wp-content/uploads/2013/10/

DOC5_PECS2009-2012_15Maio.pdf >. Acesso em: 10 ago. 2015.

COX, R. W. Production, power, and world order: social forces in the making of history. New York: Columbia University Press, 1987.

CUNHA, T. R. Bioética crítica, saúde global e a agenda do desenvolvimento. 2014. 196 f. Tese (Doutorado em Bioética) - Universidade de Brasília, Brasília, DF, 2014.

CUNHA, T. R.; LORENZO, C. Bioética global na perspectiva da bioética crítica. Rev. Bioét., Brasília, DF, v. 22, n. 1, p. 116-125, jan./abr. 2014.

DURANTE, A. L.; DAL POZ, M. R. Saúde global e responsabilidade sanitária brasileira: o caso da erradicação da poliomielite. Saúde debate, Rio de Janeiro, v. 38, n. 100, p. 129-138, jan./mar. 2014.
FEDATTO, M. S. Os desafios da cooperação internacional em saúde para o governo Dilma Rousseff. Mundorama [Internet], mar. 2015. Disponível em: $<$ http://www.mundorama.net/2015/03/26/os-desafiosda-cooperacao-internacional-em-saude-para-ogoverno-de-dilma-rousseff-por-maira-s-fedatto/> . Acesso em: 20 jul. 2015.

FOUCAULT, M. Microfísica do Poder. 26. ed. Rio de Janeiro: Edições Graal, 1979.

Des supplices aux cellules: dits et écrits. Paris: Gallimard, 1994. v. 1.

GARRAFA, V. Ampliação e politização do conceito internacional de bioética. Rev. Bioét., Brasília, DF, v. 20, n. 1, p. 9-20, jan./mar. 2012.

GIOVANELLA, L. et al. Panorama de la Atención Primaria de Salud en Suramérica: concepciones, componentes y desafíos. Saúde debate, Rio de Janeiro, v. 39, n. 105, p. 300-322, abr./jun. 2015.

JUNGES, J. R. Direito à saúde, biopoder e bioética. Interface (Botucatu), Botucatu, v. 13, n. 29, p. 285-295, abr./jun., 2009.

LORENZO, C. Teoria crítica e bioética: um exercício de fundamentação. In: PORTO, D. et al. Bioéticas, poderes e injustiças: 10 anos depois. Brasília, DF: CFM; Cátedra Unesco de Bioética; SBB, 2012. p. 173-189.

MIGNOLO, W. Desobediência Epistêmica: a opção descolonial e o significado de identidade em política. Cadernos de Letras da UFF, Niterói, n. 34, p. 287-324, 2008.

OBSERVATÓRIO BRASIL E O SUL. Cooperação Internacional para o Desenvolvimento [Internet]. Disponível em: <http://obs.org.br/cooperacaointernacional-para-o-desenvolvimento $>$. Acesso em: 15 ago. 2015.

OLIVEIRA, M.; LUZIVOTTO, C. Cooperação Técnica Internacional: aportes teóricos. Rev. Bras. Polít. Int., 
Rio de Janeiro, v. 54, n. 2, p. 5-21, jul./dez. 2008.

ORGANIZAÇÃO DAS NAÇÕES UNIDAS (ONU).

Nairobi outcome document of the high-level United

Nations conference on South-South Cooperation, Sessão, 64, 2009. Disponível em: <http://bioeticaediplomacia. org/wp-content/uploads/2013/10/GA-resolutionendorsed-Nairobi-Outcome-21-Dec-09.pdf >. Acesso em: 10 ago. 2015.

\section{ORGANIZAÇÃO DAS NAÇÕES UNIDAS PARA A} EDUCAÇÃO, A CIÊNCIA E A CULTURA (UNESCO). Relatório Mundial da UNESCO: investir na diversidade cultural e no diálogo intercultural. Paris, 2009.

\section{ORGANIZAÇÃO PAN-AMERICANA DA SAÚDE} (OPAS); ORGANIZAÇÃO MUNDIAL DE SAÚDE

(OMS). A saúde e as relações internacionais: seu vínculo com a gestão do desenvolvimento nacional da saúde. $48^{\circ}$ Conselho diretor, Sessão do Comitê Regional, 60, Washington, 29 de set. a 3 de out., 2008. Disponível em: <http://bioeticaediplomacia.org/wp-content/ uploads/2013/10/a-sade-e-as-relaes-internacionaisseu-vnculo-com-a-gesto-do-desenvolvimentonacional-da-sade-documento-e-resoluo.pdf $>$. Acesso em: 10 ago. 2015.

QUIJANO, A. Colonialidade do poder, eurocentrismo e América Latina. In: LANDER, E. (Org.). A colonialidade do saber: eurocentrismo e ciências sociais. Buenos Aires: CLACSO, 2005.

RESTREPO, E.; ROJAS, A. Inflexión decolonial: fuentes, conceptos y cuestionamientos. Universidad del Cauca: Popayán, out. 2010. (Políticas de la alteridad).

ROA, A. C.; SANTANA, J. P. Saúde e integração regional na América Latina. In: ENCONTRO NACIONAL ABRI, 3., 2011, São Paulo. Anais... Associação Brasileira de Relações Internacionais. Instituto de Relações Internacionais - Universidade de São Paulo (USP).

Disponível em: <http://www.proceedings.scielo.br/
scielo.php?script=sci_arttext\&pid=MSC00000001220 $11000100002 \& \operatorname{lng}=\mathrm{en} \& \mathrm{nrm}=\mathrm{abn}>$. Acesso em: 10 maio 2016.

SANTANA, J. P.; FERREIRA, J. R. Relevância da Bioética para a Cooperação Internacional em Saúde. Bioética, Brasília, DF, v. 6, fasc. 1-4, p. 7-8, 2010.

SECRETARIA-GERAL IBERO-AMERICANA (SEGIB). Relatório da cooperação Sul-Sul na IberoAmérica, 2. Madri, 2008. Disponível em: <http://segib. org/documentos/por/sur_sur_web_PT.pdf >. Acesso em: 12 jun. 2015.

SEGATTO, R. La cuestión descolonial. Lima: Universidad Ricardo Palma, 2010.

SOUZA, T.; CUNHA, G. T. A gestão por meio da avaliação individualizante e competitiva como elemento comum nas políticas públicas e gerenciais contemporâneas: uma contribuição crítica a partir de Michel Foucault. Saúde debate, Rio de Janeiro, v. 37, n. 99, p. 655-663, 2013.

TORRONTEGUY, M.; DALLARI, S. O Papel das Organizações Não-Governamentais na Cooperação Internacional em Saúde Pública. Saúde Soc., São Paulo, v. 21, n. 2, p. 314-322, 2012.

\section{UNITED NATIONS DEVELOPMENT PROGRAMME} (UNDP). The millennium development goals report.

New York: United Nations, 2013. Disponível em: <http://www.un.org/millenniumgoals/pdf/ report-2013/mdg-report-2013-english.pdf >. Acesso em 21 jul. 2014.

Recebido para publicação em novembro de 2015

Versão final em fevereiro de 2016

Conflito de interesses: inexistente

Suporte financeiro: não houve 